\title{
Mediação como instrumento de resolução de conflitos complexos entre povos indígenas e a República Federativa do Brasil, fundamentado no Harvard Negotiation Project
}

\author{
Mediation as a complex conflict resolution instrument between \\ indigenous peoples and the Federative Republic of Brazil, based \\ on the Harvard Negotiation Project
}

\author{
Johnattan Martins Pinheiro ${ }^{1}$ \\ Denison Melo de Aguiar ${ }^{2}$ \\ Ygor Felipe Távora da Silva
}

\begin{abstract}
RESUMO
A história da humanidade é marcada por conflitos, dentre tais o complexo embate entre povos indígenas e a República Federativa do Brasil. À vista disso, o presente artigo tem por objetivo discorrer as difículdades brasileiras no contexto dos conflitos entre à Administração Pública e os povos indígenas. Estudou-se a vasta literatura sobre a temática, baseando-se nos naturais conflitos humanos e como tal beligerância acompanha a sua história, fundamentado no Harvard Negotiation Project e instituto da mediação, como auxílio da negociação de méritos. Após observações, confirma-se que o conflito entre os povos indígenas e a República Federativa do Brasil está no choque de visões entre as partes, de um lado a visão capitalista ocidental vê a terra como um meio de obtenção de riquezas, e no outro a visão de que a terra é um ser vivo. Sendo que a principal barreira é a falta de diálogo entre as partes. Portanto, a mediação aliada ao método Harvard são a melhor solução para primeiramente desfazer essas posições para, enfim, galgarem uma real solução e não um paliativo.
\end{abstract}

\section{PALAVRAS-CHAVE:}

Mediação, administração pública, povos indígenas, negociação, pacífica.

\footnotetext{
${ }^{1}$ Acadêmico do curso de Direito da Universidade do Estado do Amazonas. Membro da Clínica de Mecanismos de Soluções de Conflitos da Universidade do Estado do Amazonas (MArbiC/UEA). Voluntário do Programa de Iniciação Científica e Tecnológica da Universidade do Estado do Amazonas 2018-2019 (ICT-UEA). Contato: johnattanmartins77@gmail.com.

${ }^{2}$ Graduado em Direito pela Universidade da Amazônia. Advogado. Mestre em Direito Ambiental pelo Programa de Pós-Graduação em Direito Ambiental da Universidade do Estado do Amazonas (PPGDA-UEA). Professor Permanente da Universidade do Estado do Amazonas (UEA). Doutorando pelo Programa de Pós-Graduação em Direito da Universidade Federal do Estado de Minas Gerias (PPGD-UFMG). Coordenador da Clínica de Mecanismos de Soluções de Conflitos da Universidade do Estado do Amazonas (MArbiC-UEA). Contato: denisonaguiarx@hotmail.com.

${ }^{3}$ Graduado em Direito pela Universidade do Estado do Amazonas. Advogado. Graduado em Administração e Ciências Contábeis pela Universidade Federal do Amazonas. Mestre em Gestão de Áreas Protegidas da Amazônia pelo Instituto Nacional de Pesquisa da Amazônia. Mestre em Direito Ambiental pelo Programa de Pós-Graduação em Direito Ambiental da Universidade do Estado do Amazonas (PPGDA-UEA). Doutor em Geografia pela Universidade Federal de Goiás. Doutorando pelo Programa de Pós-Graduação em Direito da Universidade Federal do Estado de Minas Gerias (PPGD-UFMG). Professor Permanente da Universidade do Estado do Amazonas (UEA). Membro da Clínica de Mecanismos de Soluções de Conflitos da Universidade do Estado do Amazonas (MArbiC/UEA. Contato: ysilva@uea.edu.br.
} 


\begin{abstract}
The history of humanity is marked by conflicts, among them the complex conflict between indigenous people and the Federative Republic of Brazil. In view of this, this article aims to discuss the Brazilian difficulties in the context of conflicts between the Public Administration and indigenous people. The vast literature on the subject was studied, based on the natural human conflicts and as such belligerence accompanies its history, based on the Harvard Negotiation Project and the institute of mediation, as an aid in the negotiation of merits. After observations, it is confirmed that the conflict between the indigenous people and the Federative Republic of Brazil is in the clash of visions between the parties, on the one hand the Western capitalist vision see the land as a means of achieving riches, and on the other view that the land is a living being. The main barrier is the deficiency of dialogue between the parties. Therefore, the mediation allied to the Harvard method are the best solution to first undo these positions to, in the end, reach a real solution and not a palliative.
\end{abstract}

\title{
KEYWORDS:
}

Mediation, public administration, indigenous people, negotiation, pacific.

\section{INTRODUÇÃO}

A história da humanidade é marcada pelo conflito, embora a raça humana sempre conseguiu superá-lo. Sendo este, entre membros de sua própria espécie ou de espécies exógenas. Como o Homo sapiens Neandertalensis, uma espécie do gênero Homo neanderthalensis, que habitou a Europa e alguns lugares do oeste da Ásia acerca de 230.000 a aproximadamente 29.000 anos atrás, (STRINGER; GAMBLE,1993) e as demais espécies que existem ou que foram extintas com o decorrer dos anos e da atividade humana. Tal situação de constante deliberação não poderia continuar sem resolução. Ou seja, era necessário encontrar maneiras para a resolução dessas querelas.

Primeiramente vieram à tona os métodos auto compositivos, onde as partes em conflito resolvem suas desavenças por conta própria, através de seu próprio poder, dentre eles o de maior destaque foi a violência. Onde aquele que possuísse força o suficiente para repelir, subjugar ou obrigar o outro seria o vencedor. Entretanto tal forma de resolução de conflitos era um tanto ineficaz, pois não trazia segurança. Já que aquele que venceu hoje poderia ser derrotado amanhã, e o constante caos poderia ameaçar a própria sobrevivência da espécie. 
O objetivo deste artigo é analisar como a mediação pode ser utilizada para solucionar os conflitos entre a Administração Pública e os povos indígenas através do Harvard Negociation Project, uma vez que os métodos tradicionais são ineficazes.

Esta pesquisa é socialmente relevante pois a Constituição da República Federativa do Brasil estabelece um modelo que garante aos povos indígenas a sua autodeterminação, todavia por diversos fatores estes direitos vêm sendo negligenciados.

A metodologia utilizada foi a pesquisa teórica-bibliográfica e documental. Teve-se como gênese a pesquisa bibliográfica sobre a mediação e sobre os conflitos entre os povos indígenas e a administração pública, concentrando-se nas situações que promovem o conflito e descrevendo a relação entre ambas.

Tal situação foi o germe para as soluções pacíficas auto compositivas como a conciliação, negociação e mediação, e posteriormente os métodos heterocompositivos modernos. Todavia, estes últimos, só são eficazes quando as partes em atrito estão sob o mesmo sistema jurídico. Mas o que fazer quando não estão? Como o caso da Administração Pública e os povos indígenas em suas querelas agrárias.

O artigo é estruturado ao analisar os aspectos da mediação, seguido das partes em conflito, sendo estas a Administração Pública e os Povos Indígenas para posteriormente analisar o sistema de resolução de conflitos na pós modernidade, descrevendo o processo de negociação na mediação sob a égide do sistema de negociação de méritos seguido das considerações finais.

\section{ASPECTOS DA MEDIAÇÃO}

Para obter real entendimento acerca de uma ideia, deve-se conhecer o conceito por trás da palavra. O seu significado que fica escondido a vista de todos. A palavra conflito provém do latim conflictus, que é o particípio passado de confligere que significa bater junto, estar em desavença, formado por com- (junto), acrescido de fligere (golpear, atacar) (HOUAISS A.; VILLAR M. S., 2009). 
Nas palavras de Eduardo Azar (2001), todas as espécies de conflitos "surgem da discrepância de objetivos entre duas ou mais partes que não contam com um mecanismo efetivo de coordenação ou mediação".

Dessa forma, pode-se perceber que os embates são criados e constituem forma quando não há, ou quando as formas pacíficas de solução de conflitos não promovem uma solução viável a ambas as partes. Dentre as mais comuns a mediação e a coordenação (SIGNATES,1988).

Mediação é uma palavra provém do latim mediari, que significa intervir, colocar-se entre duas partes (HOUAISS A.; VILLAR M. S., 2009). Tal conceito possui duas vertentes filosóficas principais: i. Idealista: de origem cristã, possuindo uma herança teológica, basta lembrar a mediação de Cristo entre YHVH e o homem; ii. Hegeliana: tendo como preocupação específica de explicar os vínculos dialéticos entre categorias separadas, com o seu famoso "vira-ser-de-si-mesmo" (GAMA,2015).

Entretanto, como busca-se o conceito não meramente filosófico, mas sim o pragmático. O conceito de Conselho Nacional das Instituições de mediação e Arbitragem (CONIMA) tornase mais completo:

Um processo não adversarial e voluntário de resolução de controvérsias por intermédio do qual duas ou mais pessoas, físicas ou jurídicas, buscam obter uma solução consensual que possibilite preservar o relacionamento entre elas. Para isso, recorrem a um terceiro facilitador, o mediador - especialista imparcial, competente, diligente, com credibilidade e comprometido com o sigilo; que estimule, viabilize a comunicação e auxilie na busca da identificação dos reais interesses envolvidos.

Ao tratar-se de resolução de conflitos através da mediação, não adianta focar-se somente em conceituações que embora bonitas, não servem para galgar o fim objetificado pela ação realizada, isto é, a medição. É imperioso sair da estrutura meramente acadêmica, ou melhor, é necessário trazê-la para a vida real. O conhecimento deve ser utilizado para solucionar problemas da vida real, não simplesmente ser ostentado como uma insígnia de orgulho e presunção. Da mesma forma como o ensino acadêmico tem como pedra de torque possui o tripé do ensino, pesquisa e extensão, o conhecimento deve ser útil à comunidade à sua volta.

Desta feita, a conceituação mais pragmática da mediação, e também aquela que se adequa com o objetivo proposto por este artigo é um processo de resolução autocompositiva de 
controvérsias onde as partes, antes adversárias, através de um sistema de sistema dialético, redirecionarão suas energias para a solução do conflito e não mais para a outra parte. A arte de transformar inimigos em aliados através de uma mudança do paradigma visual de ambos, fazendo-os observarem que possuem um mesmo objetivo.

\section{AS DUAS PARTES DO CONFLITO}

Para uma melhor análise do conflito, faz-se mister uma breve conceituação dos dois polos que enveredam esse dissenso. O Estado e os povos indígenas, para que dessa forma tenhase uma visão mais holística da situação, removendo dessa forma alguns equívocos que se incutem na vida da sociedade por conta da constante vivência dentro de um Estado Moderno. Pois, “deve-se ter cuidado com as coisas que estão próximas, pois quando mais se aproxima de algo, fica mais difícil de vê-lo" (INOUE, 2009). Somente através de uma visão mais holística possível conseguir-se-á analisar o conjunto de fatores que sustentam o problema a ser resolvido, sendo possível então, descobrir a melhor solução possível.

\subsection{O Estado (Administração Pública)}

O conhecido Estado Moderno, tem como marco teórico inicial o livro O Príncipe de Nicolau Maquiavel, onde é desenvolvida uma teoria da unificação do Estado Nacional através de sua máxima "os fins justificam os meios", avaliando todos os meios para alcançar o fim necessário, que se daria na concretização de uma nação com um poder centralizado' sob o qual seria capaz de tornar-se forte o suficiente para defender seus interesses individuais e de maneira indireta asseguraria os coletivos, que seria concretização de uma poderosa nação com poder centralizado e único capaz de tornar um pais forte na defesa de seus interesses coletivos. (MAQUIAVEL, 2016 e BEÇAK ,2013)

É curioso notar que Maquiavel louva essa organização porque dava mais liberdade ao rei. Agindo em nome próprio o Judiciário poderia proteger os mais fracos, vítimas de ambições e das insolências dos poderosos, poupando o rei da necessidade de interferir nas disputas e de, em consequência, enfrentar o desagrado dos que não tivessem suas 
razões acolhidas" (DALLARI, 2012).

Mas é na Revolução Francesa que esse Estado tem sua gênese de fato. Tendo como baluartes as ideias iluministas Liberté, Egalité, Fraternité, "Liberdade, Igualdade, Fraternidade" o lema foi empregado pela primeira vez em 1791 na Sociedade de Amigos dos Direitos Humanos e inspirou a difusão desses direitos nas Constituições, em organizações de trabalhadores e instituições até hoje (HOBSBAWM, 1996). Houve um rompimento com o Ancien Régime, período anterior à Revolução Francesa, um momento histórico onde o poder era através de um sistema absolutista, o poder centrado nas mãos de apenas uma pessoas com poderes absolutos sobre tudo e todos o monarca, vem do grego $\mu$ ovó $\chi \chi \eta \varsigma$ "monarkhía", de

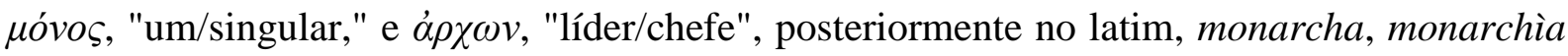
(HOUAISS A.; VILLAR M. S., 2009), a e os privilégios da nobreza reinavam (HOBSBAWM, 1996), e todos os privilégios aristocráticos tornando todas as pessoas, independentemente de seu nascimento em cidadãos iguais, consoante o art. $1^{\circ}$ da Declaração Universal do Homem e do Cidadão (FRANÇA, 1789): "Os homens nascem e são livres e iguais em direitos. As distinções sociais só podem fundamentar-se na utilidade comum”.

Retirando o poder, que outrora estava concentrado nas mãos do rei, dando-a a nação, art. $3^{\circ}$. O princípio de toda a soberania reside, essencialmente, na nação. Nenhuma operação, nenhum indivíduo pode exercer autoridade que dela não emane expressamente (FRANÇA, 1789) e partindo-o em três, Teoria da tripartidação dos poderes, onde o poder se separaria em três funções específicas que seriam atribuídas a órgãos distintos que, devido a incompletude do poder autorregular-se-ia de maneira que não haveria poder absoluto (MONTESQUIEU,2014), e em uma dessas funções, a administrativa, encontra-se o primado da Administração Pública.

Essa, que vem a ser o conjunto de órgãos que exercem a função de estabelecer diretrizes, planos de governo e políticas públicas (amplo) e o conjunto de órgãos e pessoas que executam os programas governamentais (estrito) (MEIRELLES,2007). Ou seja, sob o fulcro do princípio da Supremacia do Interesse Público, utilizando-se do poder de imperium do Estado para alcançar seus objetivos quer seja econômicos ou sociais entra em choque com os povos indígenas. Não apenas por conta dos interesses em luta. Mas principalmente por conta do choque cultural entre eles, e o problema da alteridade entre visões de mundo distintas. (FISHER; URY; PATTON, 2018 e BARRETO, 2017). 


\subsection{Os povos indígenas}

Os povos indígenas somam, segundo o Censo, 896.917 pessoas. Destes, 324.834 vivem em cidades e 572.083 em áreas rurais, o que corresponde aproximadamente a 0,47\% da população total do país (IBGE,2010).

A palavra indígena vem do latim indígena, derivação do indu, derivação arcaica do radical latino clássico "endo” (HOUAISS A.; VILLAR M. S., 2009) “movimento para dentro" acrescido de gena, derivação arcaica do radical latino clássico "genitum” (HOUAISS A.; VILLAR M. S., 2009) "gerar”. Ou seja, pessoa natural do lugar de onde vive, ente gerado na terra onde é próprio.

É um termo genérico usado pelos colonizadores para identificar os habitantes de um território anterior a sua colonização. Entretanto esse termo é muito amplo, que acaba trazendo a ideia de que todos os povos indígenas são a mesma coisa, o que não são. Cada um tem costumes, tradições, línguas que os diferem de outros povos, ainda que estejam na mesma região. Como é o exemplo dos índios da Amazônia, que apenas em questão linguísticas, podem ser separados em seis troncos linguísticos, sendo eles: Tupi, Aruque, Tukano, Jê, Karib e Pano (SANTOS,2009 e RAMOS, 2019). Por conta disso, a ONU classificou os povos indígenas em:

\footnotetext{
As comunidades, os povos e as nações indígenas são aqueles que, contando com uma continuidade histórica das sociedades anteriores à invasão e à colonização que foi desenvolvida em seus territórios, consideram a si mesmos distintos de outros setores da sociedade, e estão decididos a conservar, a desenvolver e a transmitir às gerações futuras seus territórios ancestrais e sua identidade étnica, como base de sua existência continuada como povos, em conformidade com seus próprios padrões culturais, as instituições sociais e os sistemas jurídicos (LUCIANO,2006).
}

Os povos indígenas, são um modelo de comunidades independentes do Estado, com costumes e ordenamento jurídico próprio, mas com seus territórios sobrepostos ao de um Estado, devido as levas colonizatórias, imperialistas, que desconstruíram as organizações de poder criadas entre os povos originais da terra através da conquista, pois antes do contato, os povos indígenas não estabeleciam limites territoriais fixos, no conceito que possuímos, uma vez que os mesmo viviam em um sistema de seminomadismo (SANTOS,2009). Eles andavam muito, faziam longas viagens para procurar recursos naturais em locais distantes de suas aldeias, passavam longos períodos caçando e pescando, viajavam para buscar remédios e coletar frutas e mel, entre outras atividades (SANTOS,2009 e RAMOS,2019) 
Um dos grandes desafios enfrentados pelos povos indígenas a partir do contato com os não indígenas foi a diminuição da área de seus territórios, o que impedia a ocupação do espaço segundo seus modos de vida e tradições. Tudo isso aconteceu ao longo de quinhentos anos. Primeiro houve a ocupação litorânea, aos poucos, o interior também foi sendo conquistado. Nesse processo, para garantirem seu espaço, ou sendo mais específico, aqueles que o conquistador ainda não havia ocupado, os índios adotaram diferentes estratégias: alguns entraram em guerra com os conquistadores, outros mudaram de território, caminhando em direção ao interior. Muitas vezes esses movimentos de fuga para o interior resultavam em guerras, pois quando um povo chegava em um novo território tinha que disputá-lo com outro grupo indígena que já vivia ali, gerando assim, o mesmo problema criado na África e Leste Europeu, povos com culturas totalmente distintas sendo obrigados a ocupar porções a mesma porção de terra (SANTOS, 2009 e LUCIANO,2006)

Esse germe, criado a mais de meio milênio fez nascer um problema que atormentam os governos e os autores de Teoria do Estado. Como harmonizar duas soberanias, ou mais, sob um mesmo território? Sendo que entre estas soberanias há pontos de vista distintos em relação à terra e outros pontos intrínsecos às suas cosmovisões (BARRETO, 2017 e ZAFFARONI,2010).

A Constituição da República Federativa do Brasil de 1988 (BRASIL,1988), em seu caput do artigo 231 define que: "São reconhecidos aos índios sua organização social, costumes, línguas, crenças e tradições, e os direitos originários sobre as terras que tradicionalmente ocupam, competindo à União demarcá-las, proteger e fazer respeitar todos os seus bens.”. Nas Disposições Constitucionais Transitórias, fixou-se em cinco anos o prazo para que todas as Terras Indígenas no Brasil fossem demarcadas. Mas, devido a questões políticas e econômicas o prazo não se cumpriu, e as demarcações ainda são um assunto pendente (LUCIANO, 2006). Sendo que vive-se sob a Égide de um Estado Constitucional Democrático de Direito, mas por conta de interesses privados ou mesmo pela desídia estatal, vive-se em um Estado Constitucionalmente Inconstitucional pois as garantias individuais expendias pelo texto magno estão se tornando letra morta, um total descaso pelo objetivo áureo estipulado pelo Legislador Constitucional Originário (BRASIL, 1988 e LUCIANO, 2006). 


\section{A MEDIAÇÃO E PLURALIDADE EM CONFLITOS PÓS MODERNOS}

Com o advento da pós-modernidade baseada na quebra com valores tradicionais e a explosão do multiculturalismo que se baseia na relação pacífica entre várias culturas em um mesmo ambiente sendo extremamente ligado com o fenômeno da globalização. A ideia de um grupo multicultural pressupõe que os grupos culturais estariam cada vez mais interligados, em função do crescente contato que as culturas têm entre si e a quase inexistência de grupos isolados (BAUDRILLARD, 2009 e BAUMAN,2001).

Denotando-se a um relativismo cultural onde questiona a ideia de que os hábitos e costumes de um grupo poderiam ser superiores a outros. Esta ideia de que as culturas são diversas e devem ser respeitadas na sua essência, sem existir um certo ou errado nos costumes, é a base do multiculturalismo (BAUMAN,2001 e CAPRA, 1966). Esse ponto abre a possibilidade de não apenas resolver o problema dos povos indígenas e a Administração Pública, mas acabar de vez com os atritos. Pois o maior inimigo da solução pacífica dessa controvérsia é a visão deturpada de que realmente é o índio e de sua relação com a terra (ZAFFARONI, 2010).

Os povos indígenas vivem em uma relação de simbiose com a terra. Vendo-se como uma extensão da natureza, a Pachamama que:

\footnotetext{
La Pachamama es una deidad protectora - no propiamente creadora, interesante diferencia - cuyo nombre proviene de las lenguas originarias y significa Tierra, en el sentido de mundo. Es la que todo lo da, pero como permanecemos en su interior como parte de ella, también exige reciprocidad, lo que se pone de manifiesto en todas las expresiones rituales de su culto (ZAFFARONI,2010).
}

Sendo a terra não apenas um bem, necessário a sua subsistência. Mas uma mãe que zela por seus filhos e em troca pede que seja zelada e protegida por eles, sendo além de mãe uma extensão de suas próprias vidas, conectando-os com o resto do mundo físico e espiritual. Pela qual seus filhos darão suas vidas para mantê-la.

Esse paradigma, adquirido através dos povos indígenas, projeta uma compreensão da comunidade em harmonia, respeito e equilíbrio com todas as formas de vida. Tendo como referente o viver em plenitude, esses povos religam as noções disjuntivas do projeto da modernidade, na medida em que compreendem que na vida tudo está interconectado e é interdependente. (WOLKMER, A., AUGUSTIN, \&WOLKMER, M., 2012, p. 56). 
Neste contexto que a mediação se tornar a peça fundamental para a resolução pacífica, pois A mediação é um instrumento que resolve o litígio sem sacrificar os direitos assegurados pela Constituição Federal como: "Art.1 ${ }^{\circ}$, III- "a dignidade da pessoa humana"; “Art.4, III"autodeterminação dos povos"; Art.4, VII- "solução pacífica dos conflitos" (BRASIL,1988). E no plano do processo de acordo a Lei No 13.140, de 26 de junho de 2015 (Lei da Mediação) garante em seu "art.2 : II - "isonomia entre as partes"; V - "autonomia da vontade das partes"; e A aplicarão um nível de linguagem e procedimentos que não privilegiem o lado do Estado; art.2 III - oralidade; IV - informalidade (BRASIL,2015).

Tal previsão é de sua importância, uma vez que já estipulam que a mediação não será feita objetivando simplesmente o interesse econômico, mas sim o bem estar das pessoas ali envolvidas ( $\operatorname{art.1}{ }^{\circ}$, III da $\mathrm{CF} / 88$ ), além de garantir àqueles que possuem um modo de vida diferente do "padrão nacional" que seu estilo de vida será respeitado (art.4\%, III da CF/88), fulcrando-se no diálogo, no poder da argumentação e da palavra e na violência e no poder das armas (art.4,VII da CF/88). Levando em consideração que a Administração Pública possui um nível de argumentação e retórica que pode vir a prejudicar os povos indígenas no momento da negociação, a Lei de Mediação, já prevendo tal situação, estabelece que as partes devem ter "paridade de armas" nenhum pode se sobressair sobre o outro com o finto de equilibrar a balança $\left(\operatorname{art} .2^{\circ}\right.$, II) para efetivar este equilíbrio, fica estabelecido que as duas partes devem entrar em acordo sem que sua vontade seja tolhida $\left(\operatorname{art} .2^{\circ}, \mathrm{V}\right)$ e no quesito linguagem, para maximizar a negociação e reduzir o entraves gerado pelo choque de cultura a oralidade é prevalecente sobre a forma escrita(art. $2^{\circ}$,III) retirando do horizonte de eventos da mediação as formalidades imanentes do estado sendo preferível a transcendência da informalidade gerando um ambiente mais confortável para a tomada de decisão (art. $\left.2^{\circ}, \mathrm{IV}\right)$.

Desta feita, uma vez que se trata de ordenamentos jurídicos diferentes, o Estado com o formal e os povos indígenas com o informal, a mediação consegue propiciar um enfoque mais voltado a busca cooperativa de soluções, não ordenado fazer isso ou aquilo (MARASCHIN,2017). Mas sim criar um ambiente propício ao diálogo das partes e, através dessa dialética fazer com que as partes entrem em consenso, chegando ao que chama-se de negociação colaborativa, onde busca-se a resolução do problema com resultados práticos e da mesma forma que a manutenção da harmonia entre os agora não mais beligerantes, mas sim 
colaboradores, as partes poderão expor seu pensamento e terão uma oportunidade de solucionar questões importantes de um modo cooperativo e construtivo (FISHER; URY; PATTON, 2018).

O objetivo da mediação é prestar assistência na obtenção de acordos, que poderá constituir um modelo de conduta para futuras relações, num ambiente colaborativo em que as partes possam dialogar produtivamente sobre suas necessidades (CONIMA).

Como o exemplo de Luciane Barreto (BARRETO,2017), onde houve um conflito entre os modelos médicos ocidentais com os métodos tradicionais, que na verdade, só houve conflito por conta de um estereótipo errado da parte dos médicos para com os métodos tradicionais.

\begin{abstract}
A equipe médica do hospital aceitou realizar mais uma reunião conosco. Achávamos, com isso, que estava garantido o tratamento conjunto, mas não foi o que aconteceu. $\mathrm{Na}$ sala de reunião, num lado sentou-se a equipe médica, e, no outro, sentamos nós e nossos especialistas. $\mathrm{O}$ chefe da equipe médica, sem muita conversa, de modo raivoso e arrogante, dirigiu-se a meu pai perguntando: por que o senhor acha que não deve amputar o pé de sua neta? Meu pai, sem falar bem o português, começou a responder, dizendo que do ponto de vista dele, como kumu, o pé de sua neta não estava necrosado, pois a cor roxa do pé era uma reação do sangue com o veneno da cobra. $\underline{\mathrm{O} \text { médico, }}$ visivelmente irritado, interrompeu a fala de meu pai, e esmurrando na mesa disse "eu estudei oito anos para ter autoridade para decidir o que é que melhor para um paciente, enquanto o senhor (com muito respeito), não frequentou um dia sequer a medicina". Dizendo isso se retirou, levando consigo toda a equipe. (Grifo nosso) (BARRETO, 2017).
\end{abstract}

Ou seja, a intolerância e a pretensão de estar certo por conta do estudo técnico foram os motivadores do conflito, que se houvessem, de maneira franca ouvissem os pontos de discordância e se abrissem para um diálogo, encontrariam um meio termo que possibilitaria a melhor solução.

\begin{abstract}
Com a repercussão do fato na mídia, uma equipe de outro hospital público decidiu convidar-nos para uma conversa. Durante a reunião, nossos especialistas tiveram oportunidade de apresentar suas técnicas e formas de tratamento à base de bahsese e plantas medicinais. Num diálogo bastante sincero, levando em conta os riscos e probabilidades de sucesso, foi feito um acordo formal para o tratamento conjunto. Com tal acordo, a menina foi internada no hospital. Assim, todas as vezes em que as enfermeiras faziam o curativo no pé de minha sobrinha, os kumuã entravam com procedimentos de bahsese. Como resultado desse esforço, o pé da minha sobrinha não foi amputado, perdendo apenas alguns movimentos como consequência. Hoje ela vive na comunidade/aldeia São Domingos Sávio, no Rio Tiquié, alto Rio Negro, longe da cidade e dos médicos. (Grifo nosso) (BARRETO, 2017).
\end{abstract}

Quando realmente as partes buscam uma solução definitiva, os resultados aparecem, e a mediação é a melhor, se não única, forma de realmente as partes, e não um terceiro encontrem a solução tão buscada. Mas não se pode olvidar o fato de que as partes não apenas tem de estar 
dispostas a negociar, mas também tem que saber como negociar. Este último ponto é o principal empecilho na resolução de conflitos (BARRETO,2017 e ZAFFARONI, 2010).

\section{PROCESSO DE NEGOCIAÇÃO NA MEDIAÇÃO}

Ao falar-se de negociação deve-se apagar da mente a ideia de conflito (FISHER; URY; PATTON, 2018). A negociação não é uma operação matemática proporcional, de modo que se um ganha o outro proporcionalmente só poderá perder. Hodiernamente não mais existe apenas o ideal de hierarquia de decisões, antes essas pirâmides agora se tornam teias de negociação. Ou seja, deve-se aprender a negociar (MARASCHIN,2017 e FISHER, URY, PATTON, 2018).

A primeira situação que faz-se mister evitar em uma negociação é negociar posições, negociar posições é a forma-padrão de negócios, onde cada parte se coloca em uma posição e argumenta e faz concessões para chegar a um acordo, a típica situação vaivém (MARASCHIN,2017 e FISHER; URY; PATTON, 2018), pois essa forma de negociação ao ser avaliada pelos critérios de levar a um acordo sensato, eficiente e que melhore a situação das partes, mostra-se ineficaz desde o início, pois seu princípio é tomar posições para depois abrir mão delas. O que na prática prejudica muito mais do que ajuda. Conforme o exemplo dos Estados Unidos e União Soviética em 1961 em suas negociações sobre os testes nucleares, onde interromperam o diálogo sobre uma possível suspensão dos testes nucleares simplesmente por uma discussão sobre quantidade de inspeções seriam feitas nos territórios dos dois países, sem ao menos definir como seriam essas inspeções (FISHER; URY; PATTON,2018).

A negociação de posições faz com que as partes se foquem suas energias em competir um com o outro ao invés de focar no problema, de modo que a mediação se torna improdutiva ou, na melhor das hipóteses demorada. Todavia, não se pode objetivar a substituição simples e imediata do sistema de posições pela abordagem gentil, método aposto ao de posições onde se vê o outro lado como amigo e privilegia o relacionamento aos resultados (FISHER; URY; PATTON,2018), pois como essa tem uma abordagem mais passiva, se a outra parte utilizar uma abordagem firme, outro nome para conclamar a negociação de posições, (FISHER; URY; PATTON, 2018) será facilmente estraçalhado. Então qual o melhor método? 
Assim como o Direito, em suas teorias sempre tem uma que é uma teoria transmutada de duas opostas, na negociação também ocorre o mesmo fenômeno. No Projeto de Negociação de Harvard foi criado um método que é o melhor substituto para a negociação de posições, que é chamado de negociação de méritos. Na Negociação de Méritos há quatro pontos fundamentais que auxiliam a resolução do conflito que são pessoas, interesses, opções e critérios (MARASCHIN,2017 e FISHER; URY; PATTON, 2018).

\subsection{Os pontos fundamentais da Negociação de Méritos}

\subsubsection{Pessoas}

Esse ponto foca-se no fato de os seres humanos serem indivíduos racio-emocionais, de maneira que por possuírem formas distintas de ver a mesma coisa, acabam tendo posicionamentos distintos, não necessariamente errados, e ao se focarem em suas posições acabam associando-a a sua própria identidade. Fazendo com que lute não necessariamente em busca de resultados mas sim para "proteger" aquilo que ele acredita que realmente são seus objetivos. Portanto, tudo é levado para o lado pessoal (MARASCHIN,2017).

Por isso, é imperioso manter o foco nos interesses mútuos e não em um posicionamento rígido na negociação. Revisando opiniões, procurar saber realmente o que as partes desejam, ver além da pessoa e penetrar no âmago da controvérsia, como na situação dos Kumu procurar ouvir o que realmente eles queriam (BARRETO,2017).

\subsubsection{Interesses}

Este é o fim que se deseja com a negociação, a posição é apenas uma decisão tomada sob o reflexo desse interesse, podendo existir múltiplas posições para apenas um interesse (MARASCHIN,2017). As posições tratam-se apenas de uma, diante de diversas, possibilidades com as quais uma pessoa vem a representar um interesse, posições podem ser modificadas e adequadas em prol da obtenção de um interesse. Por isso que é imperioso que as partes sejam extremamente específicas nos pontos de negociação, de modo que venham a reconhecer o seu 
interesse e o da outra parte, como um ditado árabe "quem não compreende um olhar tampouco há de compreender uma longa explicação”. Sendo rígido em não vaguear por veredas distantes desses interesses, sem, contudo, perder a urbanidade e o espírito construtivo "...deve criar situações que lhes sejam favoráveis..." (TZU, 2011, p.29), por tal motivo é necessário especificar o máximo possível os interesses, uma vez que em vias de adequar as posições haverá uma mobilidade (negociação) existe o risco de divagar por mares desconhecidos e serem tragados por correntes e contracorrentes que os afastem da costa, destarte a necessidade de traçar bem qual será a estrela Polaris que os orientará nestes mares tormentosos . E em situações de entraves procurar o "porquê" e sugerir outras alternativas. Sendo recomendável o uso da Maiêutica, em detrimento do confronto direto. A maiêutica socrática consiste em uma técnica que consiste na multiplicação de perguntas as quais induzirão o interlocutor na descoberta, per $s i$, de suas verdades e na conceituação geral de um objeto na medida em que se reponde uma série de perguntas simples, quase ingênuas, porém deveras capciosas (RODRIGUES, 2017).

\subsubsection{Opções}

Ao se falar em opções, tem-se como ponto fulcral o enfoque no preparo, nunca se deve dar início a uma negociação caso possua se tenha apenas uma opção, conforme a célebre frase de Abraham Lincoln "Dê-me seis horas para derrubar uma árvore e passarei as quatro primeiras afiando o machado.”. Não há uma resposta única, esse é o pior entrave que existe caso não possua preparo, caso o tenha, essa torna-se a melhor saída. Muitos mediadores ou negociadores ainda acreditam que a resolução é um jogo de soma zero, esquecendo que: “...não existe as partes em absoluto. Aquilo que é comumente chamado de parte, é meramente um padrão de uma inseparável rede de relações...são redes de relações encravados em redes maiores." (CAPRA,1996).

No mundo negocial, as coisas não podem ser resumidas a uma fórmula matemática, o mundo real, é um local complexo, com diversas situações que tecem uma gigantesca malha que compõe as relações humanas, e por conta desta própria complexidade que a incompletude se faz presente, como demonstra os teoremas da Incompletude de Gödel (1995) ao demonstrar matematicamente que a incompletude é intrínseca aos sistemas lógicos complexos, uma vez que o mesmo afirma que enquanto se utilizar de conceitos desde universo, nunca se conseguirá 
resolver por completo os problemas do universo, devido o fato de que somente algo/alguém de fora do sistema e utilizando ferramentas transcendentes a este sistema, conseguirá, de maneira completa entender este sistema, dentre eles podemos adicionar as relações humanas mediadas pela linguagem.

As palavras produzem ondas superficiais e profundas na mente, provocando uma série infinita de reações em cadeia, implicando sons e imagens, em um movimento que afeta a experiência e a memória, complicando o efeito de que a mente não assiste passiva a representação, mas intervêm continuamente, para aceitar, negar, destruir ou construir (RODARI, 1982), e é através destes códigos verbais e não-verbais, conhecidos como linguagem, que deve-se encontrar aquilo que realmente objetiva-se as partes, e para isso, temse uma infinidade de possibilidades para galgar o fim almejado.

"Existem apenas cinco (sic) notas na escala musical, mas suas combinações são inimagináveis; somente cinco cores básicas, mas nunca fora possível contemplar a totalidade de suas infindáveis misturas; há cinco sabores, mas suas variações são ilimitadas” (TZU,2011). Através do choque de interesses advindos da relação negocial obter-se-á uma quantidade exponencial de possibilidades, mas nem todas serão as melhores. Cabe então ao mediadornegociador filtra-las centrando as partes naquelas onde será possível galgar o maior índice possível de satisfação para as duas partes.

$\mathrm{Na}$ maioria esmagadora das vezes não se consegue criar um acordo com a ideia principal, aquela com a qual inicialmente chega-se a mesa de negociação, por isso é importantíssimo chegar preparado e saber as situações do conflito, a parte adversa, o conhecimento da situação lhe concederá uma visão mais vantajosa (FISHER; URY; PATTON, 2018 e TZU,2011).

\subsubsection{Critérios}

Embora uma infinidade de possibilidades sejam um fator favorável em relação a possibilidade de chegar em uma solução. A mesma situação pode se tornar uma Espada de Dâmocles, na anedota de Cícero representa a insegurança daqueles que possuem um grande poder, o vulto da danação iminente (CÍCERO). Por conta disso, faz-se necessário a definição 
de critérios objetivos, claros. De modo que possa ser analisado imparcialmente e provoque a sensação de que o proposto é justo, razoável, compreensível e, principalmente, aplicável. Esses critérios objetivos devem ser rígidos e não podem ceder a pressões das partes. Lembre-se que será por meio deles limitado racionalmente as opções do BATNA Best Alternative to a Negotiated Agreement, a melhor alternativa de acordo na negociação. A determinação dela é fundamental para que concessões ou imposições sejam realizadas. Porém, nem sempre consegue-se definir qual, ou quais são as melhores alternativas possíveis para determinado conflitos. Desta forma torna-se também crucial a definição da ZOPA, ou zona de possível acordo. A Zona de possível acordo é a diferença entre a BATNA de ambos os negociadores, onde a flexibilidade torna-se elemento fundamental para a concretização do processo. (FISHER; URY; PATTON, 2018), proporcionando assim uma redução do estresse e preservando o relacionamento e possibilitando futuros negócios.

Esses critérios tem de ser analisados caso à caso, podem ser opiniões científicas, reciprocidade, tratamento igualitário, uma vez que para cada conflito os fatores podem ser distintos, todavia um dos principais critérios que são encontrados na maioria das relações conflituosas entre os povos indígenas e a Administração Pública é o direito à voz, pois o que pode-se notar através da análise dos conflitos é que um dos fatores que contribuem para a insatisfação é justamente não sentir-se autor da resolução de conflitos e sim mero espectador, e assim como o ditado latino "suae quisque fortuna faber est", o homem é arquiteto de seu próprio destino (tradução livre), todos desejam ser arquitetos do seu próprio destino.

\section{CONSIDERAÇÕES FINAIS}

Diante da análise feita neste artigo, pode-se observar que o horizonte de eventos do conflito entre os povos indígenas e a República Federativa do Brasil está no choque de visões entre as partes, de um lado a visão capitalista ocidental vendo a terra como um meio de obtenção de riquezas, e no outro a visão de que a terra, é um ser vivo (Pachamama, Gaia) onde vivem em simbiose, humanos, plantas, animais. Sendo que a principal barreira é a falta de diálogo entre as partes, devido a um estereótipo pré-desenvolvido principalmente por parte do Estado, como 
foi caso de Luciane Barreto, que ao concretizar o diálogo houve o trabalho em conjunto dos médicos e do Kumu (um tipo de pajé para os não indígenas) e deu origem ao Bahserikowi Centro de Medicina Indígena (BARRETO,2017).

De forma que a mediação juntamente com o estilo de negociação de Harvard são o carro chefe para a abertura de diálogos e estreitamento de laços, sendo a única capaz, de garantir os direitos outrora conquistados pelos povos indígenas e abrir caminho para a criação e manutenção da cultura de paz. Englobando conceitos da tradição indígena e do globalizado Estado. E a tomada dos trabalhos de revisão da legislação ordinária e inclusão de novos temas no debate jurídico relativo aos índios, não mais tentando trazer os índios à comunhão social, mas respeitar suas diferenças e seu modo de vida. Deixando para trás a visão clássica da negociação e da tomada de decisões, deixando de usar o método de Negociação de Posições, que mostra ser ultrapassado para conflitos complexos trazendo resultados ínfimos ao ser comparado com a Negociação de Méritos (FISHER; URY; PATTON, 2018).

Pode-se perceber que o maior problema na resolução do conflito Brasil X Povos indígenas é o fato de que tem se focado no problema e não na solução, em lutar contra o outro e não contra o problema, trata-se de um conflito para mostrar quem está errado e não como pode-se efetivamente chegar a uma solução que beneficie ambos os lados. É claro que a Negociação de Méritos não é perfeita, principalmente por conta do fator humano das negociações, mas é impossível dizer que os resultados estão sendo muito melhores do que a forma tradicional de resolução de conflitos (CONIMA eZAFFARONI,2010). Não adianta criar um Código com a mais avançada técnica jurídica se o problema não é jurídico, social, estaremos como um paciente, diagnosticado com tuberculose ingerindo medicamentos para hepatite. Assim como um construtor antes de dar forma a sua criação deve analisar minuciosamente onde irá erguê-la, os legisladores não devem criar leis de forma leviana, mesmo que sejam boas. Pois mesmo leis boas podem tornar-se ruins caso os destinatários das mesmas não estejam preparados para recebê-las (PINHEIRO; AGUIAR; LIMA, 2019)

Mas é possível perceber que tanto os povos indígenas quanto o Estado desejam encontrar uma solução para os seus conflitos, só que falham na abordagem, devido as posições que tomaram, portanto, a mediação aliada ao método Harvard são a melhor solução para primeiramente desfazer essas posições para enfim, através dos quatro fundamentos, galgarem 
uma real solução e não um paliativo. Pois não há uma diferença preponderante entre solucionar um grande problema e um pequeno, tudo é questão de organização.

\section{REFERÊNCIAS}

ALEXANDRINO, Marcelo. Direito administrativo descomplicado. 17. Ed. rev., atual. E ampl. Rio de Janeiro: Forense; São Paulo: MÉTODO, 2009.

BARRETO, João Paulo Lima. Bahserikowi- Centro de medicina indígena da Amazônia: concepções e práticas de saúde indígena. Amazon, Rev. Antropolog. (Online) 9(2): 594-612, 2017.

BAUDRILLARD, Jean. A sociedade de consumo. $3^{\mathrm{a}}$ ed, Edições 70, 2009.

BAUMAN, Zygmunt. Modernidade líquida. 1ed. Rio de Janeiro: Zahar,2001

BEÇAK, Rubens. A soberania, o estado e sua conceituação. Revista da Faculdade de Direito da Universidade de São Paulo. V.108. p.343-351. jan/dez.2013. Disponível em : http://www.revistas.usp.br/rfdusp/article/download/67988/pdf_13/. Acesso em: 5 jan. 2019.

BRASIL, Lei $N^{o} 13.140$, de 26 de junho de 2015. Lei da Mediação. Dispõe sobre a mediação entre particulares como meio de solução de controvérsias e sobre a auto composição de conflitos no âmbito da administração pública; altera a Lei no 9.469, de 10 de julho de 1997, e o Decreto no 70.235, de 6 de março de 1972; e revoga o § 2o do art. 6oda Lei no 9.469, de 10 de julho de 1997. Disponível em: <http://www.planalto.gov.br/ccivil_03/_ato20152018/2015/lei/113140.htm>. Acesso em: 09 maio 2019.

BRASIL. Constituição da república Federativa do Brasil: promulgada em 5 de outubro de $1988 . \quad$ Disponível em: http://www.planalto.gov.br/ccivil_03/constituicao/constituicaocompilado.htm. Acesso em: 30 dez. 2019

CAPRA, Fritjot. A teia da vida: Uma nova compreensão científica dos sistemas vivos. Tradução de Newton Roberval Eíchemberg. São Paulo: Cultrix,1966.

CÍCERO. Tusculanas. Disponível em: <http://www.thelatinlibrary.com/cicero/tusc1.shtml>; <http://www.thelatinlibrary.com/cicero/tusc3.shtml>.Acesso 24 out. 2018.

CONIMA. Regulamento modelo mediação. Disponível em: < http://www.conima.org.br/regula_modmed > Acesso em: 06 set. 2018.

DALLARI, Dalmo de Abreu. Elementos da teoria geral do Estado. 3ed. São Paulo: Saraiva.2012. 
FISHER, Roger; URY, William; PATTON, Bruce. Como chegar ao sim: como negociar acordos sem fazer concessões. Tradução de Rachel Agavino. Ed., ver. E atual. Rio de Janeiro: Sextante, 2018.

FRANÇA. Declaração de direitos do homem e do cidadão. 1789. Disponível em: < http://www.direitoshumanos.usp.br/index.php/Documentos-anteriores-\%C3\%A0cria\%C3\%A7\%C3\%A3o-da-Sociedade-das-Na\%C3\%A7\%C3\%B5es-at\%C3\%A91919/declaracao-de-direitos-do-homem-e-do-cidadao-1789.html>. Acesso em 24 set. 2018.

GAMA, Zacarias. A categoria mediação em Hegel, Marx e Gramsci: para suprimir ruídos conceituais. CIÊNCIA \& LUTA de CLASSES DIGITAL, Rio de Janeiro, 46“ano,Vol. 2, N. 2, pag. 1-10, julho/2015.Disponível em: < https://ceppes.org.br/revista/edicoes-anteriores/edicaojulho-de-2015-n-3-v-3/a-categoria-mediacao-em-hegel-marx-e-gramsci-para-suprimir-ruidosconceituais/view>. Acesso em: 07 mar. 2020.

GODEL, Kurt. Some basic theorems on the foundations of mathematics and their implications in Solomon Feferman. 1951. 1995. Collected works / Kurt Gödel, Vol. III. Oxford University Press: 304-23. Disponível em: $<$ https://books.google.com.br/books?id=xH7ADAAAQBAJ\&pg=PA241\&lpg=PA241\&dq=\% 22Some+basic+theorems+on+the+foundations+of+mathematics+and+their+implications +in+ Solomon+Feferman. $\% 22 \&$ source $=$ bl\&ots=pNz4ycIM-

B\&sig=ACfU3U3V1qWuoeOTRImdaFk9ofBIbIsTFQ\&hl=pt-

BR\&sa $=$ X\&ved=2ahUKEwiYsObTt9foAhV-

JrkGHRIfBEMQ6AEwAHoECAwQLw\#v=onepage\&q=\%22Some\%20basic\%20theorems $\% 2$ 0on $\% 20$ the $\% 20$ foundations $\% 20 \mathrm{of} \% 20$ mathematics $\% 20$ and $\% 20$ their $\% 20$ implications $\% 20 \mathrm{in}$ \%20Solomon\%20Feferman.\%22\&f=false>. Acesso em: 07 mar. 2020.

HOBSBAWM, Eric J. A era das revoluções. 9.ed. São Paulo: Paz e Terra, 1996

HOUAISS, A.; VILLAR, M. S. Dicionário Houaiss de Língua Portuguesa. Elaborado pelo Instituto Antônio Houaiss de Lexicografia e Banco de dados da Língua Portuguesa S/C Ltda. Rio de Janeiro: Objetiva, 2009.

IBGE, Censo 2010. Disponível em: <https://censo2010.ibge.gov.br/noticiascenso?busca $=1 \& \mathrm{id}=3 \& \mathrm{idnoticia}=2194 \& \mathrm{t}=$ censo-2010-poblacao-indigena-896-9-mil-tem305-etnias-fala-274\&view=noticia > Acesso em: 30 set. 2019.

INOUE, Joe. "Closer”. Me!Me!Me!. Ki/oon Records, 2009. Disponível em: < https://www.youtube.com/watch?v=4Cp0WgkgDbQ>. Acesso em 24 set. 2019.

LUCIANO, G.S. O Índio Brasileiro: o que você precisa saber sobre os povos indígenas no Brasil de hoje. Edições MEC/Unesco, 2006. Disponível em: < http://www.trilhasdeconhecimentos.etc.br/livros/arquivos/ColET12_Vias01WEB.pdf >. Acesso em: 30 set. 2011.

MAQUIAVEL, Nicolau. O Príncipe: Comentado por Napoleão Bonaparte. Tradição: Pietro Nassatti. $7^{a}$ ed. São Paulo: Editora afiliada, 2016. 
MARASCHIN, Márcia Uggeri (Org.). Manual de negociação baseado na Teoria de Havard. Escola da Advocacia-Geral da União Ministro Victor Nunes Leal. Brasília: EAGU. 2017.

MEIRELLES, Hely Lopes. Direito Administrativo Brasileiro. 33 ${ }^{\mathrm{a}}$ Edição. Atualizada por Eurico de Andrade Azevedo, Délcio Balestero Aleixo e José Emmanuel Burle Filho. Malheiros Editores. São Paulo, 2007.

MONTESQUIEU, Charles de Secondat Baron de. Do espírito das leis. Trad. Roberto Leal Ferreira. São Paulo: Martin Claret.2014

PINHEIRO, Johnattan Martins; AGUIAR, Denison Melo de; LIMA, Adriana Almeida. A influência da pós verdade e da modernidade líquida na resolução consensual de conflitos. In: VIVAS, Alessandra Bentes T. et. al.(Org.). Intedisciplinaridade das políticas públicas. Rio de Janeiro : Pembroke Collins. 2019. v. 1p.774 -790.

RAMOS, Jefferson Evandro Machado. Índios da Amazônia. Sua Pesquisa.2019 Disponível em: https://www.suapesquisa.com/indios/indios_amazonia.htm. Acesso em: 30 set. 2019.

RODARI, Gianni. A gramática da fantasia. 7ª ed. São Paulo: Summus Editorial. 1982

RODRIGUES, José Paz. Sócrates e seu método da maiêutica e a ironia. PGl.gal. 2017. Disponível em: pgl.gal/socrates-metodo-da-maieutica-ironia. Acesso em: 07 jan. 2020.

SANTOS, Francisco Jorge dos. História geral da Amazônia. 3ed. Rio de Janeiro: MEMVAVMEM. 2009.

SIGNATES, Luiz. Estudo sobre o conceito de mediação. São Paulo, SP: Novos Olhares, 1988. Disponível em: <http://www.tjap.jus.br/portal/images/stories/documentos/Eventos/Texto--Estudo-sobre-o-conceito-de-mediacao.pdf>. Acesso em: 06 set. 2018.

STRINGER, Christopher; GAMBLE, Clive. In search of the neanderthals: solving the puzzle of human origins. London: GB. Thames and Hudson. 199. Disponível em: eprints.soton.ac.uk/391482. Acesso em 22 mar. 2019.

TSU, Sun. A arte da guerra: os treze capítulos originais; adaptação e tradução de André da Silva Bueno. São Paulo: Jardim dos Livros, 2011.

WOLKMER, Antonio Carlos; AUGUSTIN, Sergio; \& WOLKMER, Maria de Fatima S. O "novo" Direito à água no constitucionalismo da América Latina. Revista Internacional Interdisciplinar INTERthesis, Florianópolis, vol. 9, n. 1, jan./jun. 2012. Disponível em: < = https://periodicos.ufsc.br/index.php/interthesis/article/view/1807-1384.2012v9n1p51/22506>. Acesso em: 20 mar. 2020.

ZAFFARONI, Eugenio Raúl. La naturaleza como persona: de la Pachamama a la Gaia. Em. Bolívia: Nueva Constituición Política del Estado. Conceptos elementales para su desarrolho normativo, 109-132. La Paz: Vicepresidencia del Estado Plurinacional de Bolivia.2010. Disponível em:<https://webcache.googleusercontent.com/search?q=cache:fKTO4VeYxckJ:https://ediscip linas.usp.br/pluginfile.php/4482518/mod_folder/content/0/Zaffaroni_- 
_De_la_Pachamama_a_la_Gaia.pdf\%3Fforcedownload\%3D1+\&cd=1\&hl=ptBR\&ct=clnk\&gl=br>. Acesso em: 20 mar. 2020.

Data de Submissão: 07/04/2020

Data de Aceite: 10/05/2020 